\title{
Assessment of the effective dose to personnel in interventional radiology: a review of methods
}

\author{
C. PETRUCCI ${ }^{1}$
}

(Manuscript received 2nd August 2007, accepted 13 October 2007)

\begin{abstract}
The individual monitoring of the occupational exposure in interventional radiology is problematic, owing primarily to the fact that the personnel has to wear a lead rubber protective apron. Indeed the dosimeter readings are not, in principle, accurately representative for the effective dose in all working conditions, irrespective of the over or under-apron dosimeter location. Therefore different simulations for this kind of exposure have been performed, which assess the effective dose from the doses to tissues and derive its relationship with the monitor readings. After briefly enquiring into the general approach to the effective dose estimate in the actual practice, the present paper firstly describes in this connection the characteristics of the radiation striking the staff in interventional radiology. Then it provides, within a unified framework and through a uniform notation, a review of the literature on the effective dose assessment from the doses to tissues relatively to this type of exposure. Specific results of a certain operative relevance are examined in some detail and particular attention is devoted to identify the most appropriate method for the effective dose estimate from the dosimeter readings. Which method is finally properly modified to conform it to the forthcoming update of the effective dose definition.
\end{abstract}

RÉSUMÉ Évaluation de la dose efficace pour le personnel en radiologie interventionnelle : examen des méthodes employées.

Le contrôle individuel de l'exposition professionnelle en radiologie interventionnelle pose problème ; la raison principale est le fait que le personnel est tenu de porter un tablier protecteur en caoutchouc plombé. En effet, les doses lues ne sont pas, par principe, représentatives de la dose efficace dans toutes les conditions de travail, sans égards à l'emplacement du dosimètre, au dessus du tablier, ou au-dessous. Diverses simulations des expositions de ce genre ont donc été effectuées, afin d'évaluer la dose efficace à partir des doses aux tissus, et d'en déduire la relation qui la lie aux valeurs lues sur le moniteur. Après une brève enquête sur le cheminement conduisant à l'estimation de la dose efficace dans la pratique actuelle, notre article décrit d'abord, dans ce contexte, les caractéristiques du rayonnement qui atteint le personnel en radiologie interventionnelle. Employant un canevas unifié et une notation uniforme, il passe en revue ce qui a été publié sur l'évaluation de la dose efficace à partir des doses aux tissus, dans le cas d'expositions de ce type. Il examine en détail les résultats spécifiques d'une certaine importance opérationnelle; il porte une attention particulière à l'identification de la méthode qui convient le mieux pour évaluer la dose efficace depuis les lectures de doses. Enfin, il apporte à cette méthode les modifications adéquates pour l'adapter à la modernisation à venir de la définition de la dose efficace.

Keywords: interventional radiology / individual monitoring / effective dose / two dosimeters

\footnotetext{
${ }^{1}$ ISPESL, Department of Occupational Hygiene, via Fontana Candida 1, 00040 Monte Porzio Catone (Roma), Italy
} 


\section{Introduction}

The term interventional radiology is commonly intended to describe a group of diagnostic and therapeutic procedures percutaneously performed under fluoroscopic guidance. The use of such procedures, especially the therapeutic ones, is continually growing and expanding over many application fields. As compared with surgical techniques, they are in fact less invasive, more cost-effective and quick enough to be undertaken in day-hospital too.

The individual monitoring of the occupational exposure during this activity is problematic, because primarily of the fact that the personnel has to wear a lead rubber protective apron. It generally makes use of a single dosimeter, mostly located on the front of the trunk over the protective apron or, if present, over the thyroid collar. Sometimes the dosimeter is located under the apron, at thorax or waist level. Clearly, owing to the apron attenuation, the doses measured outside and over the apron are well above the effective dose received by the personnel. The exposure overestimate due to considering them equal may unreasonably prejudice the radiation safety program credibility and leads to a limitation of the activity or, conversely, to avoid the individual monitoring. By contrast, if the effective dose is assumed to be represented by the under-apron measurements, then its underestimate can compromise the compliance with the principles of optimization and individual dose limitation.

Different simulations of the occupational exposure in interventional radiology have been carried out which assess the effective dose from the doses to tissues and derive the relationship between the effective dose and the over or under-apron dosimeter measurements (Borasi et al., 2001; Faulkner and Marshall, 1993; Huyskens et al., 1994; Kicken et al., 1999b; Mateya and Claycamp, 1997; Niklason et al., 1994, 1993). Some algorithms have been proposed to derive the effective dose from the readings of two dosimeters, one worn over the apron and one under the apron, since this estimate is less sensitive to the working conditions than that obtained from a single dosimeter readings (Borasi et al., 2001; Niklason et al., 1994, 1993; Rosenstein and Webster, 1994).

In this paper, we firstly enquire into the general approach to estimating the effective dose in the routine practice, examining in this connection the characteristics of the radiation striking the staff in interventional radiology. Then we present, within a unified framework and through a uniform notation, a review of the existing literature on the effective dose assessment from the doses to tissues for this kind of exposure. Specific results having important operative implications are evidenced; particular attention is devoted to identify the most appropriate method for the effective dose estimate from the dosimeter readings. This might be useful to improve the effectiveness of the personnel monitoring service in the hospital and to harmonize the record of dosimetric data from national or international surveys. Finally, conclusive considerations are developed in view of the forthcoming update in the 


\section{TABLE I}

Tissue weighting factors $w_{T}$ adopted in ICRP Publication 60 (ICRP, 1991) and in the revised recommendations (ICRP, 2007).

Facteurs de pondération cellulaire $w_{T}$ adoptés dans la publication 60 de la CIPR (ICRP, 1991) et dans les recommandations révisées (ICPR, 2007).

\begin{tabular}{lcc}
\hline Tissue or organ & & $w_{T}$ \\
\cline { 2 - 3 } & ICRP 60 & Draft report \\
\hline Gonads & 0.20 & 0.08 \\
Colon & 0.12 & 0.12 \\
Lung & 0.12 & 0.12 \\
Red bone marrow & 0.12 & 0.12 \\
Stomach & 0.12 & 0.12 \\
Bladder & 0.05 & 0.04 \\
Breast & 0.05 & 0.12 \\
Liver & 0.05 & 0.04 \\
Oesophagus & 0.05 & 0.04 \\
Thyroid & 0.05 & 0.04 \\
Bone surface & 0.01 & 0.01 \\
Skin & 0.01 & 0.01 \\
Brain & & 0.01 \\
Salivary glands & & 0.01 \\
Remainder & $0.05^{\mathrm{a}}$ & $0.12^{\mathrm{b}}$ \\
\hline
\end{tabular}

${ }^{\mathrm{a}} w_{T}$ is applied to the mass-weighted average of the doses to the following 10 tissues and organs: adrenals, brain, kidneys, muscle, pancreas, small intestine, spleen, thymus, upper large intestine, uterus. In the special cases in which one of the remainder tissues receives a higher dose than any of the twelve individual organs, $w_{T}=0.025$ is applied to that tissue and $w_{T}=0.025$ is applied to the average dose in the rest of the remainder tissues.

${ }^{\mathrm{b}} w_{T}$ is applied to the arithmetic average of the doses to the following 13 tissues and organs for each sex: adrenals, extrathoracic region, gall bladder, heart, kidneys, lymphatic nodes, muscle, oral mucosa, pancreas, prostate $\left(\sigma^{7}\right)$, small intestine, spleen, thymus, uterus/cervix $(Q)$

effective dose definition. In particular, it is shown that by a suitable modification, the aforementioned method can be made to be in accordance with that revision.

\section{Effective dose estimate in the actual practice: the case of the interventional radiology}

The central protection quantity effective dose $E$ was adopted by the International Commission on Radiological Protection (ICRP) in its basic recommendation issued as Publication 60 (ICRP, 1991). In the case of external photon irradiation, it was defined by

$$
E=\sum_{T} w_{T} D_{T}
$$


where $D_{T}$ is the absorbed dose averaged over the tissue or organ $T$ and the weighting factor $w_{T}$ takes account of the tissue radiosensitivity. As shown in Table I, twelve individual organs and a group of organs collectively referred to as the remainder were identified in Publication 60.

A revised version of these recommendations, recently approved, will soon be published (ICRP, 2007). It adopts a modified and extended set of tissue weighting factors, which is also shown in Table I. All studies presently available in literature have been based on the current values of $w_{T}$ : therefore, unless stated otherwise, hereafter the effective dose is intended to be assessed by using these values. As it can be inferred from Table I, the main changes involve gonads, breast and remainder. These two individual organs, as well as all or part of most of the remainder organs are shielded by the protective apron, which is typically $0.5 \mathrm{~mm}$ lead-equivalent thick, although it can also be thinner, usually in the back portion of wrap-around aprons.

Since the weighting factors are not strictly physical parameters, the effective dose is not directly measurable. Therefore the protection system includes the operational quantity deep dose equivalent $H_{p}(10)$, in terms of which the dosimeters can be calibrated according to standardised procedures. An extensive set of monoenergetic conversion coefficients for the protection and operational quantities relevant to idealized irradiation geometries are presented in the two joint issues ICRP Publication 74 and ICRU Report 57 (ICRP, 1997; ICRU, 1998). Most of the conversion coefficients for photons assume as normalizing physical quantity the air kerma free-in-air, characterizing the incident radiation field which would exist when the individual was not present. Comparisons between the data for $E$ and $H_{p}(10)$ show that the measurement of $H_{p}(10)$ by a dosimeter on the trunk front provides a close estimate of $E$ in Anterio-Posterior (AP) and rotational geometries at energies above about $50 \mathrm{keV}$.

Nevertheless, mostly because of protective clothing, the personnel in interventional radiology receive an extremely non-uniform exposure, which therefore might not be modelled by idealized exposure conditions. Furthermore the protective clothing attenuation is affected by the tube voltage, which is typically about $80 \mathrm{kVp}$ (kilo-volt-peak), with mean spectral energy of about $45 \mathrm{keV}$, but it can be some tents of $\mathrm{kVp}$ less or higher than this value. However, the tube potential can fluctuate within a single procedure.

Using ThermoLuminescence Dosimeters (TLDs), Kicken et al. (1999a) have measured the air kerma $K_{T L D}$ at ten locations (head, neck, thorax, arms ( $\left.\times 2\right)$, hands $(\times 2)$, lower legs $(\times 2)$ and abdomen), outside or over the protective clothing, on staff performing diagnostic and interventional endovascular procedures from three 


\section{TABLE II}

Annual entrance doses to operators ( $\mu \mathrm{Gy} /$ procedure) measured in (Kicken et al., 1999a). Doses annuelles à l'entrée pour les opérateurs ( $\mu \mathrm{Gy} /$ opération) mesurées par Kicken et al. (1999a).

\begin{tabular}{|c|c|c|c|c|c|c|c|c|c|c|}
\hline & \multirow[t]{2}{*}{ Forehead } & \multirow[t]{2}{*}{ Thyroid } & \multicolumn{2}{|c|}{ Upper arma } & \multirow[t]{2}{*}{ Thorax } & \multirow[t]{2}{*}{ Abdomen } & \multicolumn{2}{|c|}{ Lower leg ${ }^{\mathrm{a}}$} & \multicolumn{2}{|c|}{ Hand $^{\mathrm{a}}$} \\
\hline & & & High & Low & & & High & Low & High & Low \\
\hline $\begin{array}{l}1^{\circ} \text { hospital - } \\
\text { undercouch tube }\end{array}$ & 8 & 20 & 56 & 6 & 25 & 37 & 120 & 72 & 72 & 27 \\
\hline $\begin{array}{l}2^{\circ} \text { hospital - } \\
\text { undercouch tube }\end{array}$ & 16 & 25 & 31 & 12 & - & - & 38 & 24 & 64 & 21 \\
\hline $\begin{array}{l}3^{\circ} \text { hospital - } \\
\text { overcouch tube }\end{array}$ & 43 & 110 & 180 & 43 & - & 39 & 15 & 8 & 215 & 75 \\
\hline
\end{tabular}

${ }^{\mathrm{a}}$ Distinction is made between extremities with high and low exposure.

hospitals in the Netherlands. Table II lists the annual averages of the measurements on operators converted into entrance doses

$$
\mathcal{D}^{\text {entrance }}=\frac{\left(\mu_{\mathrm{en}} / \rho\right)_{T}}{\left(\mu_{\mathrm{en}} / \rho\right)_{\text {air }}} K_{T L D}
$$

by using the ratio of mass energy absorption coefficients of tissue and air.

From these data it emerges that the distribution of the incident radiation field is nonuniform itself and is affected by the tube configuration, exhibiting higher levels to the lower and upper part of the body in undercouch and overcouch configuration, respectively. Moreover the difference between the entrance dose at two body sides evidences that the exposure occurs from lateral-frontal rather than AP direction. From the issues ICRP Publication 74 and ICRU Report 57 it can be estimated a ratio $E_{\mathrm{AP}} / E_{45^{\circ} \text { oblique }} \cong 1.2$ between the effective dose received for the anterior and anteriorly $45^{\circ}$ oblique incidence of an irradiation at $45 \mathrm{keV}$.

\section{Effective dose assessment from the doses to tissues}

Specific dosimetric studies have been undertaken on the occupational exposure in interventional radiology, due primarily to the extreme non-uniformity and secondarily to the obliquity of the irradiation. Almost all assess the doses $D_{i, T}$ to the portions of the organ $T$ within different regions $i$ distinguished in the body. This is important since this method enables to better model exposure conditions for which certain tissues or large organs (such as the red bone marrow) are partially shielded by the lead apron and partially left unshielded.

Organ portion dose conversion coefficients have been already computed relatively to the exposure of patients undergoing routine X-ray examinations, for 
instance in (Wall et al., 1988); these computations do not consider oblique projections.

\subsection{The Faulkner and Marshall analysis}

In the experimental work of Faulkner and Marshall (1993) a beam produced by a tube at 70,90 and $110 \mathrm{kVp}$, in both the over and undercouch configurations, was directed toward an abdomen phantom. The scattered radiation struck a Rando phantom, representing the radiologist, loaded with numerous TLDs within the slices or on the surface at locations corresponding to the various radiosensitive organs. The dose to skin, bone surface, red bone marrow and remainder were estimated as $D_{T}=\sum_{i} f_{i, T} D_{i, T}$ where $f_{i, T}$ is the organ $T$ total mass fraction in slice $i$.

The doses to organs partially or totally shielded by a lead apron were estimated from the unshielded measured doses by

$$
D_{T}=(1-s) D_{T}+s t D_{T}
$$

where $s$ is the shielded organ fraction and $t$ the scattered radiation transmission.

It has emerged that, as the lead-equivalent thickness is increased from 0 to $0.5 \mathrm{~mm}$, the effective dose tends towards a constant value. This trend is due to the contribution from unshielded organs becoming dominant. In particular the effective dose was observed to drop off negligibly for thicknesses greater than about $0.4 \mathrm{~mm}$ in the case of irradiation at $90 \mathrm{kVp}$ in overcouch configuration. Therefore, increasing the apron thickness above such value would increase the weight supported by workers without leading to a significant radiation protection improvement.

\subsection{The Niklason analysis}

The study by Niklason et al. $(1994,1993)$ used the unshielded organ doses normalized to the entrance dose which are listed in Table III. Those for marrow and bone surface of head and neck and that for the thyroid were taken from the tables in (Wall et al., 1988) relevant to the AP projections of skull and cervical spine, for $80 \mathrm{kVp}$ and filtration of $3 \mathrm{~mm}$ aluminium. The normalized doses to the other organs in head, neck and extremities, which are not included in the tables (Wall et al., 1988), were calculated multiplying the depth dose, as obtained from the charts in (Harrison, 1981), by the fraction of the organ within the region of interest. The sum of the normalized doses to each tissue in head, neck and extremities was multiplied by the respective tissue weighting factor as recommended in ICRP Publication 60. All these terms, which are listed in the last 
TABLE III

Normalized doses to the unshielded organs and their contributions to the effective dose as obtained in (Niklason et al., 1994, 1993).

Doses normalisées aux organes non protégés. Leurs contributions à la dose efficace selon Niklason et al. $(1994,1993)$.

\begin{tabular}{|c|c|c|c|}
\hline \multirow[t]{2}{*}{ Organ or tissue } & \multicolumn{2}{|c|}{$D_{T} / \mathcal{D}^{\text {entrance }}$} & \multirow{2}{*}{$w_{T} D_{T} / \mathcal{D}^{\text {entrance }}$} \\
\hline & Head and neck & Extremities & \\
\hline Red bone marrow & 0.017 & 0.010 & 0.0032 \\
\hline Bone surface & 0.100 & 0.600 & 0.0070 \\
\hline Skin & 0.050 & 0.370 & 0.0042 \\
\hline Oesophagus & 0.100 & & 0.0050 \\
\hline Thyroid & 0.794 & & 0.0397 \\
\hline
\end{tabular}

$\mathcal{D}^{\text {entrance }}$, entrance dose.

column of Table III, were added for the purpose of determining the total contribution to the effective dose from all the unshielded regions in case of thyroid collar absence. The terms relevant to thyroid and oesophagus were excluded from the sum for the case of thyroid collar presence. The two resulting values were increased by $5 \%$ to take account of the remainder and finally approximated, respectively, to 0.06 and 0.02 .

Taking into consideration the dominating influence of the unshielded organs on the effective dose, these results demonstrate that, when the thyroid is not shielded, this organ dose accounts for the greatest contribution to the effective dose and can be larger than half of the total.

\subsection{The Huyskens analysis}

Huyskens et al. (1994) started from the monoenergetic organ dose conversion coefficients computed by the German National Research Center for Environment and Health. Then they determined the conversion coefficients spectrally weighted for the unshielded scattered radiation $d_{T}^{o}$, and for the radiation hardened after transmission through the apron $d_{T}^{u}$. The computations were repeated for AP, Posterior-Anterior (PA) and LATeral (LAT) irradiations. Some different combinations of these three geometries $(g)$, each lasting the time fraction $t_{g}$, were considered and the organ dose conversion coefficients were calculated as

$$
d_{T}=\sum_{g} t_{g}\left[(1-s) d_{T}^{o}+s t d_{T}^{u}\right]
$$

where $s$ and $t$ are defined the same as in equation (1). 
The use of wrap-around and frontal aprons was simulated for different transmissions and shielded organ fractions. As a result, this study has demonstrated that the protection afforded by wrap-around aprons is much better in LAT and PA geometry, and is less sensitive to the exposure geometry and differences in the apron fit.

\subsection{The Mateya and Claycamp analysis}

Mateya and Claycamp (1997) irradiated with an AP primary beam an anthropomorphic phantom loaded with TLDs and wearing a protective apron, with and without a thyroid collar, both $0.5 \mathrm{~mm}$ lead-equivalent thick. Therefore a direct organ dosimetry through the lead apron was made. The doses to the unshielded organs and to the thyroid were adjusted, using published data, from plane-parallel to fluoroscopy irradiation conditions.

For a primary beam having the same ability to penetrate the lead apron as a $90^{\circ}$ scatter beam produced at $80 \mathrm{kVp}$, Mateya and Claycamp obtained a ratio between the effective dose received without and with the thyroid collar equal to 4.7 in overcouch configuration and 4.1 in undercouch configuration.

\subsection{The Kicken analysis}

While considering the body to consist of the same regions distinguished in (Kicken et al., 1999a) with addition of the thighs, Kicken et al. have computed the conversion coefficients for the organ portion doses $d_{i, T} \equiv D_{i, T} / K_{i}$ induced by an AP irradiation at $80 \mathrm{kVp}$, with filtration of $2.5 \mathrm{~mm}$ aluminium (Kicken et al., 1999b). As normalizing quantity they used the air kerma free-in-air at the region entrance $K_{i}$, assuming it to be equal to the $K_{T L D}$ measurements in (Kicken et al., 1999a) for the shielded regions and dividing the $K_{T L D}$ measurements by the body backscatter for the unshielded regions. $K_{\text {abdomen }}$ was considered to be representative also for the thighs.

The effective dose was calculated according to the expression

$$
E=\sum_{i} K_{i} \sum_{T} \frac{w_{T} d_{i, T} \operatorname{Corr}_{i, T}}{\operatorname{Att}_{i, T}}
$$

where $\operatorname{Corr}_{i, T}$ is a correction factor which takes into account that the irradiation is lateral-frontal instead of AP, that the measurements at the forehead are not completely representative for the overall head region and that the neck hole in the apron is not considered. $\mathrm{Att}_{i, T}$ includes the beam attenuation and hardening within a $0.5 \mathrm{~mm}$ lead-equivalent apron or through a thyroid collar. 


\section{TABLE IV}

Results by Kicken et al. (1999b) relevant to the percentage contribution from the different body regions to the effective dose $E$ received by operators.

Résultats de Kicken et al. (1999b) donnant, en pourcentages, la contribution des diverses régions du corps à la dose efficace $E$ reçue par les opérateurs.

\begin{tabular}{|c|c|c|c|c|c|c|}
\hline \multirow[t]{2}{*}{ Region } & \multicolumn{2}{|c|}{$\begin{array}{l}1^{\circ} \text { hospital - } \\
\text { undercouch tube }\end{array}$} & \multicolumn{2}{|c|}{$\begin{array}{l}2^{\circ} \text { hospital - } \\
\text { undercouch tube }\end{array}$} & \multicolumn{2}{|c|}{$\begin{array}{l}3^{\circ} \text { hospital - } \\
\text { overcouch tube }\end{array}$} \\
\hline & without collar & with collar & without collar & with collar & without collar & with collar \\
\hline Head & 3 & 5 & 5 & 12 & 15 & 42 \\
\hline Neck & 48 & 8 & 68 & 17 & 72 & 20 \\
\hline Upper arms & 4 & 7 & 4 & 10 & 4 & 11 \\
\hline Hands & 9 & 16 & 7 & 17 & 5 & 14 \\
\hline Thorax & 2 & 3 & 2 & 5 & 2 & 5 \\
\hline Abdomen & 7 & 13 & 6 & 10 & 2 & 7 \\
\hline Thighs & - & 1 & - & 1 & - & - \\
\hline Lower legs & 26 & 46 & 9 & 22 & 7 & 2 \\
\hline$\frac{E \text { (without collar })}{E \text { (with collar })}$ & \multicolumn{2}{|c|}{1.8} & \multicolumn{2}{|c|}{2.6} & \multicolumn{2}{|c|}{2.8} \\
\hline
\end{tabular}

The $E$ reduction achieved by a $0.5 \mathrm{~mm}$ lead-equivalent thyroid collar is also shown.

Table IV presents, for the three hospitals investigated in (Kicken et al., 1999a), the percentage contributions from the different body regions to the effective dose received by operators, as well as the ratios of the effective dose in absence of thyroid collar to that in presence of a $0.5 \mathrm{~mm}$ lead-equivalent thyroid collar. The next greatest contribution to the effective dose, after that from the unshielded neck region, is seen to come from the lower legs and head in the cases, respectively, of under and overcouch configuration.

From computations for one of the three hospitals where both the under and overcouch configurations were used, the effective dose to operators and assistants was quantified to be lower in the former case by nearly a factor 4 .

\section{Relation between effective dose and deep dose equivalent}

When going on to examine the effective dose estimate in the individual monitoring practice, the actual value is expected to be significantly below the readings of dosimeters located over the apron, and conversely above the under-apron dosimeter readings. In view of this the ratios divider $H_{p}(10)_{\text {neck }}^{\mathrm{o}} / E$ and multiplier $E / H_{p}(10)_{\text {waist }}^{u}$ are introduced, on the assumption that the dosimeters are calibrated in terms of deep dose equivalent and are located over the apron at neck level or under the apron at waist level. 
TABLE V

Divider and multiplier values obtained by Faulkner and Marshall and revised by the NCRP Report 122 (Faulkner and Marshall, 1993; NCRP, 1995).

Valeurs « divider » et « multiplier » obtenues par Faulkner et Marshall, puis révisées dans le rapport NCRP 122 (Faulkner et Marshall, 1993 ; NCRP, 1995).

\begin{tabular}{|c|c|c|c|c|c|c|c|c|}
\hline \multirow[t]{4}{*}{$\mathrm{kVp}$} & \multicolumn{4}{|c|}{ Divider } & \multicolumn{4}{|c|}{ Multiplier } \\
\hline & \multicolumn{2}{|c|}{ Undercouch } & \multicolumn{2}{|c|}{ Overcouch } & \multicolumn{2}{|c|}{ Undercouch } & \multicolumn{2}{|c|}{ Overcouch } \\
\hline & \multicolumn{8}{|c|}{ Lead-equivalent thickness (mm) } \\
\hline & 0.3 & 0.5 & 0.3 & 0.5 & 0.3 & 0.5 & 0.3 & 0.5 \\
\hline 70 & 34 & 40 & 51 & 57 & 1.2 & 4.5 & 1.8 & 6.7 \\
\hline 90 & 27 & 33 & 63 & 72 & 0.9 & 2.2 & 1.1 & 2.9 \\
\hline 110 & 25 & 35 & 21 & 31 & 0.6 & 1.1 & 0.7 & 1.4 \\
\hline
\end{tabular}

Faulkner and Marshall (1993) determined the ratio of effective dose to filmbadge measurements at various locations on the Rando phantom surface, after correcting the measurements relative to the under-apron locations for the scattered radiation transmission. The neck over-apron and waist under-apron data for 0.3 and $0.5 \mathrm{~mm}$ lead-equivalent thicknesses were revised by the NCRP Report 122 (1995) in the divider and multiplier values, relevant to the unshielded thyroid, which are shown in Table V.

The multiplier appears to be much closer to unity than the divider. In fact a single dosimeter worn under the lead apron has been considered to yield a reasonable estimate of the effective dose in (Faulkner and Harrison, 1988), and more recently by the ICRP (2001). The under-apron monitoring was recommended in reference (Faulkner and Harrison, 1988) also because it is useful to evidence an exposure increase due to an individual failing to wear the apron.

An improved effective dose estimate should require correcting the under-apron reading by a precise value of the multiplier, depending on apron thickness, tube potential and configuration. In this respect it can be noted that the sensitivity with voltage, which is a hardly controllable parameter, is larger for the multiplier than for the divider, as we evidenced in Figure 1 plotting the $0.5 \mathrm{~mm}$ lead-equivalent and undercouch configuration data from Table V. Thus it would be more legitimate to divide the over-apron doses by a single divider irrespective of the voltage, rather than multiply the under-apron doses by a single multiplier. Because of this and since the under-apron doses could be below the detection threshold, most of studies suggest that, if the effective dose is estimated using only one dosimeter, it should be located over the lead apron (Borasi et al., 2001; Huyskens et al., 1994; Kicken et al., 1999b; NCRP, 1995). 


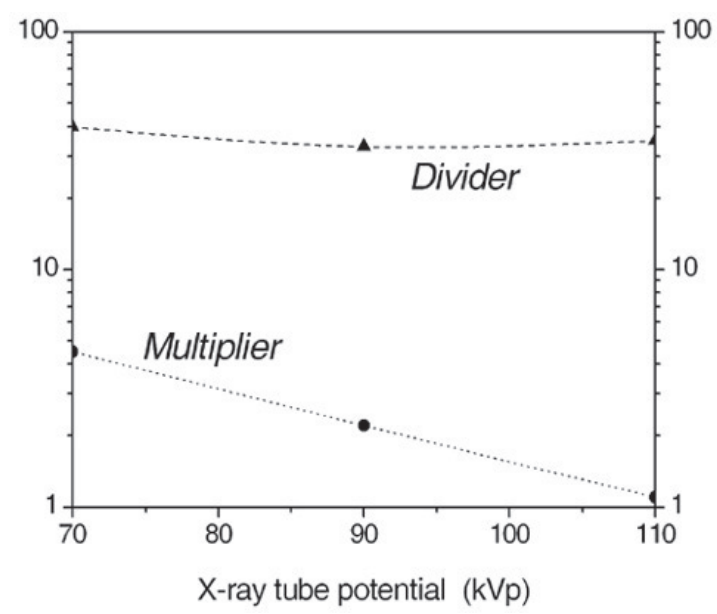

Figure 1 - Plot of the $0.5 \mathrm{~mm}$ lead-equivalent and undercouch configuration data in Table V against the tube voltage.

Graphe de l'équivalent de $0,5 \mathrm{~mm}$ de plomb et de la configuration sous-couche, portée dans le tableau $V$, en fonction de la tension appliquée au tube.

TABLE VI

Divider values derived by linear interpolation of the $0.5 \mathrm{~mm}$ lead-equivalent data in Table $\mathrm{V}$ at $80 \mathrm{kVp}$ and obtained in references (Huyskens et al., 1994; Kicken et al., 1999b; Mateya and Claycamp, 1997).

Valeurs « divider » déduites par interpolation linéaire des données, pour un équivalent-plomb de $0,5 \mathrm{~mm}$, dans le tableau $\mathrm{V}$ à $80 \mathrm{kVp}$, et obtenues dans les références suivantes : Huyskens et al. (1994), Kicken et al. (1999b), Mateya et Claycamp (1997).

\begin{tabular}{lccccc}
\hline & Faulkner and Marshall & Huyskens et al. & Mateya and Claycamp & \multicolumn{2}{c}{ Kicken et al. } \\
\cline { 2 - 6 } & \multicolumn{2}{c}{ Without collar } & With collar \\
\hline Undercouch & 36 & $(5-15)$ & 11 & $112-13)$ & $(24-32)$ \\
Overcouch & 64 & & 10 & 15 & 45 \\
\hline
\end{tabular}

In Tables VI we present the divider values derived by linear interpolation of the $0.5 \mathrm{~mm}$ lead-equivalent data in Table $\mathrm{V}$ at $80 \mathrm{kVp}$. The range of results by Huyskens et al. refer to all examined exposure conditions relative to the smallest apron transmission $t=1 \%$ (Huyskens et al., 1994). The results of Mateya and Claycamp are relevant to a direct irradiation having the same quality as a $90^{\circ}$ scatter beam produced at $80 \mathrm{kVp}$ (Mateya and Claycamp, 1997). Those of Kicken et al. pertain to the combined group of operators, assistants and workers in the operator/assistant role (Kicken et al., 1999b). 
Table VI is very useful for the sake of making a comparison among the various dosimetries, even if it must be noted that differences exist in the irradiation conditions, body models and parameter values, as well as in dosimetric quantities and accuracy of the personal monitor system. With this regard it must be pointed out, for instance, that Huyskens et al. would set the transmission of $0.5 \mathrm{~mm}$ leadequivalent thickness to $3 \%$, whilst Kicken et al. set it to $0.5 \%$. Furthermore, the divider values of Kicken et al. in Table VI represent the ratios between the neck over-apron entrance dose, instead of the deep dose, and the effective dose.

Anyway the rough comparison in Table VI evidences substantial consistence of divider values (relevant to the unshielded thyroid) among the different studies, apart from those of Faulkner and Marshall, which appear to yield a serious underestimate of the effective dose. In reference (Rosenstein, 1998) it was claimed that the results by Faulkner and colleagues $(1993,1988)$ and those by Mateya and Claycamp (1997) should not be compared because the adjustments made by these latter authors to correct the assumed plane-parallel irradiation do not account for the complex irradiation actually experienced by the clinicians. Mateya and Claycamp refused this statement in (Mateya and Claycamp, 1998), arguing lack of consistency between their own doses to the thyroid and oesophagus and those obtained in (Faulkner and Marshall, 1993). A reason for the effective dose underestimate by Faulkner and Marshall was ascribed in (Kicken et al., 1999b) to the Rando phantom having no extremities, the contribution of which can be of the order of $40 \%$, as seen from data in Table IV.

\section{Two-dosimeter algorithms}

Regardless of whether the over or under-apron monitoring is used, the fact remains that, in order to accurately estimate the effective dose, the irradiation conditions and the apron thickness should be exactly known and then the corresponding correction applied. Several authors have suggested obviating this need by using two dosimeters (Borasi et al., 2001; Faulkner and Marshall, 1993; ICRP, 2001; Niklason et al., 1994; Rosenstein and Webster, 1994). In particular, some algorithms have been proposed for estimating the effective dose as a linear combination of two monitor readings, one over and one under the protective apron (Borasi et al., 2001; Niklason et al., 1994; Rosenstein and Webster, 1994). In reference (Huyskens et al., 1994) it was emphasised that a single dosimeter is often not sufficient when the occupational dose limits may be reached.

\subsection{The Rosenstein and Webster algorithm}

Using the Faulkner and Marshall experimental findings, Rosenstein and Webster (1994) developed an empirical function of the neck over-apron and waist 
under-apron readings, which minimizes the underestimates of the effective dose and allows its close estimate at the most frequently encountered condition in clinical practice $(0.5 \mathrm{~mm}$ lead apron, $90 \mathrm{kVp}$, undercouch configuration). This formula, which can be used in case of thyroid collar absence, was rewritten in terms of deep dose equivalents

$$
E=0.025 H_{p}(10)_{\mathrm{neck}}^{\mathrm{o}}+0.5 H_{p}(10)_{\mathrm{waist}}^{u}
$$

and incorporated in the NCRP Report 122 (1995).

Substitution of the divider and multiplier values from Table $\mathrm{V}$ results in estimates ranging between $1.05 E$ and $2.03 E$. This accuracy can be compared with that relevant to the single over-apron dosimeter use. In such case, as recommended in the NCRP Report 122 (1995), the minimum value of the divider should be conservatively assumed, thus accepting to overestimate $E$ by up to divider $_{\max }$ /divider $_{\min }=72 / 21=3.4$.

\subsection{The Niklason algorithm}

Neglecting the tissue attenuation, Niklason et al. $(1994,1993)$ assigned the deep dose at waist under-apron $H_{p}(10)_{\text {waist }}^{u}$ as a whole body dose. Then they calculated the effective dose by adding to this term the contribution from all the unshielded regions. This latter, in turn, was obtained multiplying the respective conversion coefficients, for the cases of thyroid collar absence and presence, by the shallow dose equivalent at neck over-apron $H_{p}(0.07)_{\text {neck }}^{\mathrm{o}}$, decreased by the whole body dose $H_{p}(10)_{\text {waist }}^{u}$. The shallow dose was thought to be more appropriate than the deep dose, taking under consideration the fact that it was designed to monitor the dose to the skin and that the original data in Table III are normalized to the entrance dose. Namely the Niklason method (Niklason et al., 1994) proposes the two equations

$$
\begin{aligned}
E & =H_{p}(10)_{\mathrm{waist}}^{u}+0.06\left[H_{p}(0.07)_{\mathrm{neck}}^{\mathrm{o}}-H_{p}(10)_{\mathrm{waist}}^{u}\right] \\
& =0.06 H_{p}(0.07)_{\text {neck }}^{\mathrm{o}}+0.94 H_{p}(10)_{\mathrm{waist}}^{u} \quad \text { Without thyroid collar } \\
E & =H_{p}(10)_{\mathrm{waist}}^{u}+0.02\left[H_{p}(0.07)_{\text {neck }}^{\mathrm{o}}-H_{p}(10)_{\mathrm{waist}}^{u}\right] \\
& =0.02 H_{p}(0.07)_{\text {neck }}^{\mathrm{o}}+0.98 H_{p}(10)_{\text {waist }}^{u} \quad \text { With thyroid collar. }
\end{aligned}
$$

Therefore it offers the advantage over the Rosenstein and Webster method of making allowance for the thyroid collar use. 


\subsection{The Borasi algorithm}

Borasi et al. (2001) tried to recalculate the effective dose conversion coefficient for the same beam quality simulated by Kicken et al. using the monoenergetic data tabulated in (ICRP, 1997; ICRU, 1998). An higher value than in (Kicken et al., 1999b) was obtained from computation. Then they revised the dose conversion coefficients in (Kicken et al., 1999b), so that the organ portion doses add up to the mean organ doses in (ICRP, 1997; ICRU, 1998). They distinguished also the thyroid and humerus regions and defined a new data set for radiation further filtered by $0.5 \mathrm{~mm}$ lead.

To estimate the effective dose they make a separation in equation (2) between the contributions from the unshielded body regions $e_{i_{o}}=\sum_{T} w_{T} d_{i_{o}, T}$ and the analogous contributions $e_{i_{u}}$ from the shielded regions, supposing the same transmission for both the apron and the thyroid collar, if present. The air kerma freein-air at thorax entrance $K_{\text {thorax }}$ was extracted from the two resulting sums and replaced through the introduction of the conversion coefficients $h_{p}^{\mathrm{o}}$ and $h_{p}^{u}$. To wit, the former was substituted by the over-apron deep dose $H_{p}(10)_{\text {thorax }}^{\mathrm{o}}=$ $h_{p}^{\mathrm{o}} K_{\text {thorax }} B_{\mathrm{Pb}} / B_{\mathrm{H}_{2} \mathrm{O}}$, where $B_{\mathrm{Pb}} / B_{\mathrm{H}_{2} \mathrm{O}}$ takes into account the backscatter reduction due to $0.5 \mathrm{~mm}$ lead instead of water, and the latter was replaced with the underapron deep dose $H_{p}(10)_{\text {thorax }}^{u}=h_{p}^{u} K_{\text {thorax }}$. Equation (2) was eventually rewritten as

with

$$
E=H_{p}(10)_{\text {thorax }}^{\mathrm{o}} W^{\mathrm{o}}+H_{p}(10)_{\text {thorax }}^{u} W^{u}
$$

$$
W^{o}=\frac{1}{h_{p}^{o} B_{\mathrm{Pb}} / B_{\mathrm{H}_{2} \mathrm{O}} i_{o}} \sum\left(\frac{K_{i_{o}}}{K_{\text {thorax }}}\right) e_{i_{o}} \operatorname{Corr}^{\prime} i_{o} \text { and } W^{u}=\frac{1}{h_{p}^{u}} \sum\left(\frac{K_{i_{u}}}{K_{\text {thorax }}}\right) e_{i_{u}} \operatorname{Corr}^{\prime}{ }_{i_{u}}
$$

where Corr' corrects for the event of oblique or not detected irradiation and of voltage higher than $80 \mathrm{kVp}$.

A number of exposure conditions were examined. First, an uniform irradiation was simulated, both neglecting the tissue attenuation and using the conversion coefficients $e_{i_{o}}$ and $e_{i_{u}}$. Subsequently the fluoroscopy irradiations in the first and third row of Table II were considered, with the entrance dose at thorax set to $90 \mu \mathrm{Gy} /$ procedure in case of overcouch configuration. Different shielding levels by the protective clothing and corrections on the incident radiation were assumed. The two formulas were finally proposed

$$
\begin{aligned}
& E=0.12 H_{p}(10)_{\text {thorax }}^{\mathrm{o}}+1.40 H_{p}(10)_{\text {thorax }}^{u} \quad \text { Without thyroid collar } \\
& E=0.08 H_{p}(10)_{\text {thorax }}^{\mathrm{o}}+1.40 H_{p}(10)_{\text {thorax }}^{u} \quad \text { Without thyroid collar }
\end{aligned}
$$


TABLE VII

Divider values obtained from equations (3), (4) and (5). Valeurs « divider » obtenues en utilisant les équations (3), (4) et (5).

\begin{tabular}{lccc} 
& Rosenstein and Webster & Niklason et al. & Borasi et al. \\
\hline Without collar & 33 & 14 & 6 \\
With collar & & 33 & 9 \\
\hline
\end{tabular}

where the coefficients had been chosen as the highest values of $W^{o}$ and $W^{u}$ obtained from computations, further increased by a conservative overestimate.

\subsection{Comparison of the two-dosimeter algorithms}

The two-dosimeter algorithms can be reduced to the divider $H_{p}(10)_{\text {neck }}^{\mathrm{o}} / E$ values in order to easily compare them. This can be done assuming that there is no difference, in first approximation, among entrance dose, deep and shallow dose (except for the units) and that the incident radiation distribution is given by the entrance doses in the first row of Table II. Then, for a transmission $t=0.5 \%$, the relationships $H_{p}(10)_{\text {waist }}^{\mathrm{o}} \cong 0.01 H_{p}(10)_{\text {neck }}^{\mathrm{o}}$ and $H_{p}(10)_{\text {thorax }}^{u} \cong 5 \times 10^{-3} H_{p}(10)_{\text {thorax }}^{\mathrm{o}} \cong 6.25 \times$ $10^{-3} H_{p}(10)_{\text {neck }}^{\mathrm{o}}$ are obtained, substitution of which in equations (3), (4) and (5) results in the divider values shown in Table VII.

The values by Niklason et al. are seen to be in substantial agreement with those obtained for undercouch configuration in Table VI, apart from that of Faulkner and Marshall. The algorithm of Rosenstein and Webster appears to underestimate the effective dose, as expected being it based on the Faulkner and Marshall data. Conversely, the formulas of Borasi et al. overestimate the effective dose, as an obvious consequence of entering overestimated coefficients into them.

\section{Discussion and conclusions}

A comprehensive review of the studies assessing the occupational effective dose in interventional radiology from the doses to tissues has been presented. From this review it emerges the importance of using the thyroid collar, wrap-around aprons instead of those front-coverage, the undercouch configuration rather than the overcouch configuration.

Moreover we examined the methods to estimate the effective dose from the monitor readings and we focused on their comparison, calling attention to differences in the dosimetries which these methods are derived from. According to most of authors, a reliable estimate of the effective dose can be obtained by applying a reduction factor to the single over-apron dosimeter measurement. This 


\section{TABLE VIII}

Normalized doses to the unshielded organs and their contributions to the effective dose as obtained when revising the Niklason algorithm.

Doses normalisées aux organes non protégés. Leurs contributions à la dose efficace ont été obtenues en corrigeant l'algorithm de Niklason.

\begin{tabular}{lccc}
\hline Organ or tissue & \multicolumn{2}{c}{$D_{T} / \mathcal{D}^{\text {entrance }}$} & $w_{T} D_{T} / \mathcal{D}^{\text {entrance }}$ \\
\cline { 2 - 3 } & Head and neck & Extremities & 0.0032 \\
\hline Red bone marrow & 0.017 & 0.010 & 0.0070 \\
Bone surface & 0.100 & 0.600 & 0.0042 \\
Skin & 0.050 & 0.370 & 0.0040 \\
Oesophagus & 0.100 & & 0.0318 \\
Thyroid & 0.794 & & 0.0014 \\
Brain & 0.143 & & 0.0077 \\
Salivary glands & 0.770 & & \\
\hline
\end{tabular}

$D_{T}$, absorbed dose averaged over the tissue $T ; w_{T}$, tissue weighting factor adopted in the new recommendations (ICRP, 2007); $\mathcal{D}^{\text {entrance }}$, entrance dose.

statement is based on the dominating influence of the unshielded organs for thick aprons and no very high voltages.

In order to accurately estimate the effective dose in all working conditions, the need of using two dosimeters, one over and one under the apron, is commonly recognized. The two-monitor algorithm of Niklason et al. (1994) is that in better agreement with the ratios between the over-apron and effective dose reported in literature. Furthermore it allows accounting for the thyroid collar use. For example, Padovani and colleagues, after performing a review of the two-dosimeter algorithms, adopted this method in carrying out a survey on the effective dose to staff in interventional cardiology within the European DIMOND Project (Padovani et al., 2001; Padovani and Rodella, 2001).

New effective dose assessments from the doses to tissues will be performed when the revised list of the tissue weighting factors will come into use. However, it is reasonable to suppose that this will have a minor impact on the above general conclusions. Indeed, as already noted when commenting on Table I, the main changes in the tissue weighting factors involve two individual organs protected by the lead apron and the remainder tissues, most of which also are totally or partly shielded. Anyway, the specification of explicit weighting factors for the brain and salivary glands and the inclusion of the extrathoracic airways and oral mucosa amongst the remainder organs are expected to slightly increase the effective dose and to emphasize the advantage of using the undercouch configuration instead the overcouch configuration. In contrast, because of these changes and of the 
reduction in the tissue weighting factors for the thyroid and oesophagus from 0.05 to 0.04 , the benefit of using the thyroid collar would slightly be reduced.

As a conclusive note to this review, following the approach of Niklason et al., we revise their algorithm on account of the updated effective dose definition. Accordingly, Table III is changed into the corresponding Table VIII, which displays an enlarged list of the unshielded organs thus comprising the brain and salivary glands, whilst the tissue weighting factors are those in the last column of Table I. The normalized dose to the brain was taken from the table in (Wall et al., 1988) relevant to the $\mathrm{AP}$ skull projection, $80 \mathrm{kVp}$ and filtration of $3 \mathrm{~mm}$ aluminium. The salivary glands were assumed to be at an average depth of $2 \mathrm{~cm}$. Then the dose to this organ, which is not included in the tables (Wall et al., 1988), was estimated assuming it be equal to the resulting depth dose as obtained from the charts in (Harrison, 1981). For the cases of thyroid collar absence and presence, two sums were calculated, respectively, over all terms in the last column of Table VIII and with the exception of thyroid and oesophagus. The two sums were increased by $12 \%$ to take account of the remainder and approximated, respectively, to 0.07 and 0.03 . The original equations (4) were eventually modified in

$$
\begin{aligned}
E & =H_{p}(10)_{\text {waist }}^{u}+0.07\left[H_{p}(0.07)_{\text {neck }}^{\mathrm{o}}-H_{p}(10)_{\text {waist }}^{u}\right] \\
& =0.07 H_{p}(0.07)_{\text {neck }}^{\mathrm{o}}+0.93 H_{p}(10)_{\text {waist }}^{u} \quad \text { Without thyroid collar } \\
E & =H_{p}(10)_{\text {waist }}^{u}+0.03\left[H_{p}(0.07)_{\text {neck }}^{\mathrm{o}}-H_{p}(10)_{\text {waist }}^{u}\right] \\
& =0.03 H_{p}(0.07)_{\text {neck }}^{\mathrm{o}}+0.97 H_{p}(10)_{\text {waist }}^{u} \quad \text { With thyroid collar. }
\end{aligned}
$$

In the study by Niklason et al. the over and under-apron doses to a group of interventional radiologists were measured, on the base of which the mean annual doses were predicted, respectively, amounting to $H_{p}(0.07)_{\text {neck }}^{\mathrm{o}}=55 \mathrm{mSv} \mathrm{y}^{-1}$ and $H_{p}(10)_{\text {waist }}^{u}=0.88 \mathrm{mSv} \mathrm{y}^{-1}$. The application of the original algorithm yields the estimates of 4.1 and $2.0 \mathrm{mSv} \mathrm{y}^{-1}$ for the effective dose received, respectively, in absence of the thyroid collar and in presence of it (Niklason et al., 1994, 1993). Correspondingly, the updated version of the algorithm gives 4.7 and $2.5 \mathrm{mSv} \mathrm{y}^{-1}$ in the two cases, respectively. These results show that, actually, the revision of the tissue weighting factors leads to a significant though contained increment in the effective dose estimate. The thyroid collar keeps on providing a substantial protective capacity, although slightly reduced.

\section{REFERENCES}

Borasi G., Piccagli V., Tassoni D., Mondini L. (2001) Valutazione della dose efficace per il personale di radiodiagnostica che indossa il camice piombifero, Fis. Med. 3, 221-238. 
Faulkner K., Harrison R.M. (1988) Estimation of effective dose equivalent to staff in diagnostic radiology, Phys. Med. Biol. 33, 83-91.

Faulkner K., Marshall N.W. (1993) The relationship of effective dose to personnel and monitor reading for simulated fluoroscopic irradiation conditions, Health Phys. 64, 502-508.

Harrison R.M. (1981) Central-axis depth-dose data for diagnostic radiology, Phys. Med. Biol. 26, $657-$ 670.

Huyskens C.J., Franken Y., Hummel W.A. (1994) Guidance on personal dosimetry for occupational exposure in interventional radiology, J. Radiol. Prot. 14, 229-234.

ICRP Publication 60 (1991) Recommendations of the International Commission on Radiological Protection, Ann. ICRP 21.

ICRP Publication 74 (1997) Conversion coefficients for use in radiological protection against external radiation, Ann. ICRP 26.

ICRP Publication 85 (2001) Avoidance of radiation injuries from medical interventional procedures, Ann. ICRP 30.

ICRP (2007) Recommendations of the International Commission on Radiological Protection. Draft of 12 January 2007, from http://www.icrp.org/docs/ICRP_Draft_Recommendations_12_January_2007.pdf

ICRU Report 57 (1998) Conversion coefficients for use in radiological protection against external radiation, Bethesda, MD.

Kicken P.J.H., Kemerink G.J., van Engelshoven J.M.A. (1999a) Dosimetry of occupationally exposed persons in diagnostic and interventional arteriography. Part I: assessment of entrance doses, Radiat. Prot. Dosim. 82, 93-103.

Kicken P.J.H., Kemerink G.J., Schultz F.W., Zoetelief J., Broerse J.J., van Engelshoven J.M.A. (1999b) Dosimetry of occupationally exposed persons in diagnostic and interventional arteriography. Part II: assessment of effective dose, Radiat. Prot. Dosim. 82, 105-114.

Mateya C.F., Claycamp H.G. (1997) Phantom-derived estimation of effective dose equivalent from Xrays with and without a lead apron, Health Phys. 72, 842-847.

Mateya C.F., Claycamp H.G. (1998) Response to Rosenstein, Health Phys. 74, 490-491.

NCRP Report 122 (1995) Use of personal monitors to estimate effective dose equivalent and effective dose to workers for external exposure to low-LET radiation, Bethesda, MD.

Niklason L.T., Marx M.V., Chan H.P. (1993) Interventional radiologists: occupational radiation doses and risks, Radiology 187, 729-733.

Niklason L.T., Marx M.V., Chan H.P. (1994) The estimation of occupational effective dose in diagnostic radiology with two dosimeters, Health Phys. 67, 611-615.

Padovani R., Rodella C.A. (2001) Staff dosimetry in interventional cardiology, Radiat. Prot. Dosim. 94, 99-103.

Padovani R., Foti C., Malisan M.R. (2001) Staff dosimetry protocols in interventional radiology, Radiat. Prot. Dosim. 94, 193-196.

Rosenstein M. (1998) Comment on "phantom-derived estimation of effective dose equivalent from X-rays with and without a lead apron", Health Phys. 74, 489-490.

Rosenstein M., Webster E.W. (1994) Effective dose to personnel wearing protective aprons during fluoroscopy and interventional radiology, Health Phys. 67, 88-89.

Wall B.F., Harrison R.M., Spiers F.W. (1988) Patient dosimetry techniques in diagnostic radiology, IPSM Report 53, Bocardo Press Limited, Oxford. 